\title{
Disability and quality of life in pure and comorbid social phobia. Findings from a controlled study
}

\author{
H.U. Wittchen ${ }^{1}$, M. Fuetsch ${ }^{1}$, H. Sonntag ${ }^{1}$, N. Müller ${ }^{1}$, M. Liebowitz ${ }^{2}$ \\ 1 Max Planck Institute of Psychiatry, Clinical Psychology and Epidemiology Munich, Germany; \\ 2 New York State Psychiatric Institute New York, NY, USA
}

\section{Summary}

Social phobia is increasingly recognized as a prevalent and socially impairing mental disorder. However, little data is available regarding the general and disease-specific impairments and disabilities associated with social phobia. Furthermore, most studies have not controlled for the confounding effects of comorbid conditions. This study investigates: (a) the generic quality of life; (b) work productivity; and, (c) various other disorder-specific social impairments in current cases with pure $(\mathrm{n}=$ 65), comorbid $(\mathrm{n}=51)$ and subthreshold $(\mathrm{n}=34)$ DSM-IV social phobia as compared to controls with no social phobia (subjects with a history of herpes infections). Social phobia cases reported a mean illness duration of 22.9 years with onset in childhood or adolescence. Current quality of life, as assessed by the SF-36, was significantly reduced in all social phobia groups, particularly in the scales measuring vitality, general health, mental health, role limitations due to emotional health, and social functioning. Comorbid cases revealed more severe reductions than pure and subthreshold social phobics. Findings from the Liebowitz self-rated disability scale indicated that: (a) social phobia affects most areas of life, but in particular education, career, and romantic relationship; (b) the presence of past and current comorbid conditions increases the frequency and severity of disease-specific impairments; and, (c) subthreshold social phobia revealed slightly lower overall impairments than comorbid social phobics. Past-week work productivity of social phobics was significantly diminished as indicated by: (a) a three-fold higher rate of unemployed cases; (b) elevated rates of work hours missed due to social phobia problems; and (c) a reduced work performance. Overall, these findings underline that social phobia in our sample of adults, whether comorbid, subthreshold, or pure was a persisting and impairing condition, resulting in considerable subjective suffering and negative impact on work performance and social relationships. The current disabilities and impairments were usually less pronounced than in the past, presumably due to adaptive behaviors in life style of the respondents. Data also confirmed that social phobia is poorly recognized and rarely treated by the mental health system.

Keywords: comorbidity, disability, quality of life

\section{Introduction}

Social phobia (also known as social anxiety disorder) has recently been shown to be a relatively frequent, though often unrecognized and untreated disorder in the general population [1-6]. Considerable uncertainty still exists as to whether social phobia should be considered to be a 'serious' mental disorder per se from a public health perspective in terms of resulting impairments and disabilities. Although there is some evidence that patients who seek treatment frequently suffer a considerable degree of disability as well as a reduced quality of life [23, 28], such studies have neither been able to paint a complete picture of the impairments associated with social phobia, nor to determine the degree to which these impairments are due to social phobia per se, rather than to the presence of other mental disorders present in these patients. This latter consideration is of key importance because 
there is overwhelming evidence that comorbidity is extremely frequent among subjects with social phobia. Several clinical and epidemiological studies have demonstrated significantly elevated odds that social phobics also have other anxiety disorders, depressive as well as substance-use disorder [2, 6, 11, 29].

From retrospective evaluations, it is generally assumed that comorbid depressive disorders are likely to be secondary complications of social phobia [1, 29], as is the development of alcohol abuse [6-10, 17]. However, there have been no prospective longitudinal studies up until now, which have confirmed this assumption.

General population studies using fairly broad and unspecific indicators of impairments and disability have also suggested convergently that the lifetime presence of social phobia is associated with a reduced work performance, a reduced social interaction, and possibly more school problems during adolescence $[7,16]$. Although these studies do avoid the helpseeking effects inherent in clinical samples, they do have considerable limitations as well: (a) due to the lack of specific assessment instruments for social phobia-specific impairments and disabilities as well as of quality-of-life (QoL) measures, they have not been able to demonstrate in detail the range and breadth of disabilities and reduced quality of life associated with social phobia; and, (b) they have failed to control their findings for the effects of comorbid conditions. The only evidence so far that pure social phobia, uncomplicated by current comorbidity, is associated with considerably reduced quality of life and substantial disabilities, comes from a casecontrol study in 65 community respondents with pure social phobia [30]. The present study provides a further extension of these latter findings by including subthreshold and comorbid social phobia as comparison groups.

\section{Aims}

The primary aims of this analysis are to provide a more detailed picture of lifetime and current psychosocial impairments, disabilities, and handicaps associated with social phobia, as well as their impact on the patient's generic quality of life. In this respect, the paper focuses on the following outcome measures: quality of life, lifetime and current disease-specific psychosocial impairments and difficulties, work productivity and health care utilization. To study the effects of comorbidity on these outcome measures, pure and comorbid social phobia (social phobia with comorbid conditions) will be compared to a control group unaffected by social phobia. Finally, a secondary objective of this study is to examine how subthreshold social phobics differ from the pure and comorbid group. Subthreshold social phobia is defined here as social phobia not fulfilling the DSM-III-R criterion E ('interferes with occupational functioning or with usual social activities or relationships with others, or there is marked distress about having the fear' APA, 1987, page 243). Interest in this issue has been stimulated by a recent study of Davidson et al. [7] suggesting substantial impairments even in subthreshold social phobics.

\section{Materials and Methods}

The methods of this study have already been presented elsewhere in greater detail [30]. Thus the sample and the procedures used will be described only briefly here.

\section{Recruitment of subjects - Inclusion and exclusion criteria}

In order to avoid systematic helpseeking biases (for example, patients actively seeking treatment might be the most severely impaired or social phobics being afraid of contacting 
personally a mental health service), study participants were recruited through advertisements in several local daily and weekly newspapers in the greater Munich area and thus were not recruited from our inpatient and outpatient units. The advertisement asked for participation of subjects suffering from fear or avoidance of one or more social situations, listed according to the stem questions of our diagnostic study instrument, the Composite International Diagnostic Interview (CIDI) [12, 13]. Potential subjects were encouraged to contact us by phone to reduce the fear of the first contact. People who responded to this announcement were then briefly screened by a research assistant using a checklist to assess some of the inclusion and exclusion criteria. They were also told that the survey was confidential and that they would be paid a small fee. General inclusion criteria were: an age between 18 and 60 years, endorsement of at least one social phobia screening item, and a duration of social phobia problems of at least six months. Subjects with severe visual impairment and those currently being treated in medical and psychiatric hospitals or other settings were also excluded. After this telephone screening, respondents who met the criteria for entrance into the study were scheduled for a detailed clinical interview at the institute.

Overall 240 subjects responded to the announcement; 63 were excluded in the telephone screening and the remaining 177 were subselected for the personal interview. Of these, nine did not show up, 15 did not meet the DSM-III-R criteria for even subthreshold social phobia, and three did not complete all the questionnaires. Thus, 150 cases were accepted for further investigation, completed the study interview, and were subsequently assigned to one of the following social phobia comparison groups:

\section{Comparison group A: pure social phobia $(n=65)$}

From the diagnostic interview, 65 subjects were found to have a current pure social phobia and no comorbidity. Thus, this group comprised only social phobics meeting criteria for threshold social phobia according to DSM-III-R criteria, but not for current or past major depression, bipolar disorder, dependence on alcohol, medication or illegal substances, agoraphobia, panic disorder, generalized anxiety, eating disorder, dementia or psychotic disorder.

\section{Comparison group B: comorbid social phobia $(n=51)$}

This group comprised 51 comorbid subjects with current threshold social phobia according to the DSMIII-R criteria. All had lifetime or current diagnoses of major depression $(n=31$, $60.8 \%)$ and/or dysthymia $(n=16,31.4 \%$ ). Most had other additional lifetime diagnoses (the 12 month comorbidity rates are reported in table II). These were found to be most frequently alcohol abuse or dependence $(n=20,39.2 \%)$; agoraphobia with or without panic attacks $(n=$ 20, 39.2\%); panic disorder $(n=18,35.3 \%)$; generalized anxiety disorder $(n=9,17.6 \%)$; and, eating disorders $(n=9,17.6 \%)$. Four subjects had a past history of psychotic disorders, four fulfilled lifetime criteria for drug dependence, and four had an obsessive compulsive disorder (7.8\%).

\section{Comparison group C: subthreshold social phobia $(n=34)$}

Thirty-four cases met all of the current diagnostic criteria except the current impairment/distress criterion (E) of the DSM-III-R criteria. Eleven also had at least one other lifetime diagnosis (12 month comorbidity, findings are reported in table II). Three had major depressive episodes at some point in their lifetime, 11 had alcohol use disorders, one an eating disorder, two had panic with agoraphobia, and one a sedative dependence. 
In order to test our social phobia group against a group of subjects who had also suffered for several years from a physical disease with a fluctuating course, the control group was sampled from an existing database of individuals with recurrent herpetic infections which matched the pure social phobia group by age and gender (subjects were not matched for employment and marital status because both variables are believed to be a potential consequence of social phobia). In terms of impairments and the use of the health service, this constitutes a tougher test as these controls could be expected to have a reduced quality of life and to use the health services more frequently than the general population, and healthy controls in particular. The controls had responded to a similar newspaper announcement in autumn 1993. Research assistants contacted these people to assess their willingness to participate in this new study. Interested subjects responding by telephone were screened and scheduled for exactly the same clinical assessment described below for subjects with social phobia.

\section{Characteristics of the study group}

Table I summarizes the sociodemographic characteristics of the four comparison groups. With no significant between-group differences for gender and mean age, significantly more subjects in the control group (56.9\%) were married at the time of selection, compared with only 33.8\% in the pure social phobia group ( $\mathrm{P}<0.05$ ), 17.6\% in the comorbid group, and $29.4 \%$ in the subthreshold group. This difference was due to a lower number of subjects who had never been married and a higher number of divorced subjects in the social phobia groups. Social phobics were also more frequently unemployed $(\mathrm{P}<0.05)$ in comparison with controls.

\section{Interviewer and instruments}

The face-to-face interviews were conducted by nine clinical psychologists, all of whom were staff members of the Clinical Institute of the Max Planck Institute of Psychiatry in Munich. The average clinical experience of the interviewers was 2.3 years. The interviewers were all trained in the use of CIDI by the first author, who directs the official World Health Organization Training Center for CIDI. In addition, interviewers received a one day training in the use of the other assessment instruments used in this study.

\section{Psychopathology and diagnostic status}

The Composite International Diagnostic Interview - core version 1.1 (CIDI) [12], a fully structured diagnostic instrument, was used to confirm the presence of social phobia in the study group and the absence of social phobia in controls. It was also used to determine the presence of lifetime and current mental disorders according to the diagnostic algorithms of the DSMIII- R. The CIDI version 1.1 provides both ICD-10 and DSM-III-R diagnoses.

Throughout this paper only the DSM-III-R diagnoses will be reported. Diagnostic findings are reported without using diagnostic hierarchies in order to examine comorbidity. The validity, test-retest and inter-rater reliability [14-17] of the CIDI have been established.

Quality of life

As a measure of the generic quality of life the HOS-short forum (SF-36) [18, 19] was used for several reasons. This scale has the advantages of being brief, it can be self-administered, and it is comprehensive in that it measures a broad range of health concepts that are neither 
disease nor treatment-specific [18]. It also meets the psychometric standards of validity and reliability [19-21]. The SF-36 includes 36 items and requires approximately ten to 15 minutes to complete. It has been self-administered by people as young as 14 years old. The survey is available in several languages, including the German version used in this study [22]. SF-36 standardized scale scores of 50 to 70 are usually regarded as indicating moderately reduced quality of life, whereas scores below 50 indicate a markedly reduced quality of life. These threshold scores were used for some of the analysis described below.

\section{Disease-specific disabilities}

Disease-specific disabilities were assessed by the Liebowitz Disability Self-Rating Scale (LDSRS), which measures life-style impairment due to emotional problems. It considers handicaps in the areas of education, employment, family, social and romantic relationships, as well as the patient's ability to perform routine activities of daily living. The schedule consists of 11 items, each scored from ' 0 ' (no effect) to ' 3 ' (severe limitation). Evidence for the internal consistency and concurrent validity of the Liebowitz scale in social phobia have been reported [23]. In this study we compute an overall LDSRS score for the current (past four weeks) and worst time period (when the social phobia symptoms were worst), by taking the theoretical maximum score of not having any impairment as $100 \%$. Thus a mean score of 39 , for example, indicates substantial disabilities.

\section{Work productivity}

To measure work productivity, the Work Productivity and Impairment Questionnaire (WPAI) of Reilly et al. [24], was used to quantify the effect of general health and symptom severity on work productivity. Evidence of the construct validity and reproducibility of the WPAI has been presented. The WPAI measures the percentage of work time spent actually working, considering both full and part day absences. It also considers performance at work, measured as a percentage of maximal performance. The product of these two measures is called overall work productivity.

\section{Health care utilization (HSUI)}

In addition to information from the CIDI, the Health Service Use Inventory (HSUI) designed for use in clinical trials was used. It measures the number of encounters with health care providers during the two weeks preceding survey administration. Visits to physicians, visits to other practitioners, home health care visits, and inpatient and outpatient hospital stays were all considered.

\section{Results}

\section{Clinical characteristics of social phobias}

Table II shows that a clear majority (61.8\%) of subthreshold cases was classified as 'isolated' (predominantly performance or situational social fears only) social phobia, using CIDI conventions. The 'generalized' subtype is over-represented in both the pure (52.3\%) and in the comorbid group (80.4\%). Almost all subjects with generalized social phobia endorsed 'speaking fears' items of the CIDI and at least one other item (mean number of social fears endorsed, pure group: 2.8; comorbid: 4.3; subthreshold: 2.2). Almost all subjects, except for the subthreshold group, reported severe 'panic-like' anxiety reactions when being confronted with, or thinking about being exposed to, and reported predominately persistent avoidance - 
rarely endurance in such situations. Subthreshold phobics displayed lower frequencies of persistent avoidance (64.7\%) and severe anxiety reactions (67.6\%). In agreement with previous findings, only few social phobia cases had contacted a doctor or other health specialists because of their condition. Comorbid cases (51\%) had done so slightly more frequently than pure social phobia cases (35.4\%). Even fewer cases indicated having ever received some type of formal treatment because of their condition (pure: $12.4 \%$; comorbid: 19.6\%; subthreshold: $2.9 \%)$.

Among comorbid cases there is a substantial degree of current (12 month) multimorbidity. More than two thirds in the comorbid group had at least one additional 12 months diagnosis. Every second person in this group was either suffering from major depression or dysthymia, the most frequent comorbid conditions. Close to $50 \%$ also met currently criteria for agoraphobia or other anxiety disorders.

Separate attention should be given to substance use disorders and particularly to the use of nicotine and alcohol. All three groups revealed significantly increased rates of current nicotine dependence in comparison with the nicotine dependence prevalence in the general population of $29 \%$ and $27.2 \%$ in the control group. They also smoked a significantly higher number of cigarettes per day (control group mean: 11.2, SD: 6.4). Seventy-one percent of the pure, $84.3 \%$ of the comorbid, and $68 \%$ of the subthreshold social phobia cases considered themselves as regular smokers during the 12 months prior to the interview according to the CIDI (control group: 32.3\%). Similarly, the current (past year) average amount of alcohol consumed per week (measured in grams of absolute alcohol) was significantly higher in all three groups as compared to the control group (mean: 28.9, SD: 22.2). This remarkable tendency to consume alcohol is also reflected in higher rates for alcohol abuse or dependence. (Alcohol dependence was an exclusion criterion in the pure social phobia group).

The cumulative probability curve for age of onset (figure 1) of social phobia indicates that the vast majority of patients in all three social phobia groups reported the onset of their anxiety in childhood or adolescence. At the age of 20, approximately $70 \%$ in each of three groups had already fulfilled the diagnostic criteria for social phobia. We also examined how frequently social phobia occurred after the onset of another comorbid mental disorder, by comparing the respondents' retrospective age-of-onset information from the CIDI. Except for four subjects with dysthymia, three cases with eating disorders, and two subjects with alcohol or drug use disorder, all other comorbid conditions in the comorbid group were clearly secondary to social phobia by at least one year. An additional four subjects indicated an onset of panic attacks prior to the onset of social phobia; however, the onset of threshold agoraphobia or panic disorder was secondary.

Almost all social phobia subjects could be described as chronic with a mean illness duration of more than 20 years. When asked at what age their social phobia symptomatology was worst (peak episode), the subjects indicated a mean age of $26.0(\mathrm{SD}=10.0)$. We will subsequently report findings for disease-specific impairments both for the past weeks as well as for this peak episode when the symptomatology was worst.

\section{Current generic quality of life (QOL, SF-36)}

In comparison with the control group, pure social phobics revealed significantly (Wilcoxon signed rank test for matched groups) lower scores in several of the SF-36 scales indicating a reduced quality of life (figure 2 ). Significant $(\mathrm{P}<0.05)$ reductions in self-rated quality of life were evident for the following scales: GHP (general health), RE (role limitations due to 
emotional problems), SF (social functioning), GMH (general mental health), and VIT (vitality). Subthreshold social phobics and even more comorbid social phobics revealed similar or even lower SF-36 mean scores than the pure social phobia group in almost all domains.

When the respondents were sub-typed according to their standardized summed score for the three scales measuring the emotional health component (SF, GM, and VIT, table III), 23.1\% of all subjects with pure social phobia, $51 \%$ of those with comorbid, and $20.6 \%$ with subthreshold social phobia were categorized as severely impaired (score below 50), and $24.6 \%, 31.4$ and $35.3 \%$ respectively, were categorized as markedly impaired. In the control group, by contrast, only $4.6 \%$ were either severely or markedly impaired.

Thus, all three social phobia groups were significantly $(\mathrm{P}<0.01)$ more impaired than the control group. Taking together all moderately and severely impaired in the social phobia groups we can state that at least $50 \%$ of all social phobics (as compared to only $4.6 \%$ in the control group) had a markedly reduced quality of life. Furthermore, the comorbid group is significantly $(\mathrm{P}<0.001)$ more impaired than both the pure as well as the subthreshold group, whereas no significant differences were found in the comparison between the pure and the subthreshold social phobia group.

The degree of quality of life impairments was significantly related to the number of social fear situations reported $(\mathrm{df}=8, \mathrm{~F}=0.8, \mathrm{P}<0.05)$. It is also noteworthy that neither illness duration, age of onset, nor the number of depressive symptoms reported in the depression section of CIDI was significantly related to the SF-36 reductions.

\section{Disease-specific disabilities}

Figure 3 describes the subject-rated disease-specific disabilities in different domains. (We also used a clinicianrated version [disability profile] as well, although these findings are not reported here because they were almost identical). Although this scale has additional scales for suicidal ideation, alcohol and medication use, these three variables - consistent with Schneier et al. [23] - were neither used in the summary score nor reported separately in the figure.

On most of the scales, at least $50 \%$ of respondents in each group indicated at least some current impairment due to their social phobia. Overall, the ratings for the 'worst period ever' as measured as a reduction of the maximum DSRS sum score of 100 (no disability), ranged from a low of 39.9 for comorbid social phobia to 64.7 for subthreshold, and 60 for the pure social phobia group. Overall, current disabilities ranged from 67.9 for comorbid, over 82 for pure, to 87.6 for subthreshold social phobia. This indicates that social phobics generally had more severe impairments when symptomatology was at its peak as compared to the current status (Wilcoxon rank sum test for pure group: $\mathrm{P}<0.003$, for comorbid group $\mathrm{P}<0.001$ ). This finding might suggest that many cases have suffered the most severe restrictions in the past and might have 'learned' to live and cope with at least some of the impairments.

Consistent with the elevated substance use and substance use disorder rates reported above, the use of psychotropic substances seem to play a significant role in 'coping' with social phobia problems, as indicated by the elevated rates for moderation in alcohol use as well abstinence from drugs (drug findings in brackets: pure group: 0.8 [0.3], comorbid: 0.9 [0.5], subthreshold 0.6 [0.3], all group differences non-significant). The difference in the LDSRS total score between the subthreshold and the pure group was not significant. However, the 
comorbid group is significantly more impaired than the subthreshold and the pure group (Wilcoxon rank sum test: $\mathrm{P}<0.01$ ). Disabilities for pure and comorbid social phobia were most severe for romantic relationships, and similarly severe for educational attainment/career, employment (or if homemaker, household management), mood regulation, social network, other interests and family relations. Daily activities were least affected (current and worst). Consistent with this, the most severe disabilities were reported by comorbid social phobics. It is further noteworthy that there were - consistent with the previous findings of Weiller et al. [27] - remarkably high scores for the variable 'frequent suicidal ideation/diminished desire to live’ (comorbid: 2.2, pure: 1.2, subthreshold: 1.2).

\section{Professional status and work productivity (WPAI)}

In interpreting the work productivity findings one needs to take into account that a substantial number of social phobics were currently unemployed (11\% in the pure group, $22 \%$ in the comorbid group, and $12 \%$ in the subthreshold social phobia group). Most of them attributed the unemployment to their social phobia problems. The following WPAI findings only refer to those subjects who were employed or working at the time of assessment, excluding all homemakers and those being unemployed. Figure 3 indicates that social phobia is characterized by a considerable decrease in general work productivity due to illness and related emotional problems. Taking the WPAI overall-index for work productivity (ranging from $100=$ completely disabled to $0=$ no reduction), the pure social phobia (11.4) and the comorbid social phobia group (12.4) displayed a significantly higher mean WPAI index than the control group $(1.5, \mathrm{P}<0.001)$. This can be interpreted as a 11.4 to $12.4 \%$ work productivity reduction. The breakdown of some selected WPAI components used in calculation the WPAI overall index (figure 4), suggests that this is due in all three social phobia groups to an elevated number of subjects reporting at least once in the past month, complete work loss days as well as a diminished productivity when working.

\section{Health care utilization}

Except for a slight but non-significant increased rate of visits to primary care providers in all social phobia groups as compared to the control group, no increase in current health care utilization was found. Although we tried to identify whether there were subgroups of social phobia cases with a particularly high risk of heavy utilization (comorbid vs. non-comorbid, those being aware of having social phobia vs. those who are not), none of these comparison led to different findings.

\section{Conclusion}

This study is the first to examine in a non-patient sample: (a) the generic quality of life as well as diseasespecific impairments of pure social phobics, uncomplicated by lifetime and current comorbid conditions; (b) differences between comorbid and pure social phobics in terms of the range and breadth of disabilities and the reduction in quality of life; and, (c) disabilities experienced by subthreshold social phobias, on the basis of standardized assessments with regard to diagnosis, quality of life, disease-specific disabilities as well as work productivity. The social phobics examined consisted predominantly of untreated cases suffering from social phobia over two decades. The majority were suffering from fairly 'generalized' social fears, except for the subthreshold group in which fairly isolated social phobia prevailed. The use of a control group of people suffering from a recurring physical disorder (herpetic infections) instead of a healthy control group, allowed a stringent and more difficult test of how social phobia affects quality of life. 
The study subjects were recruited through newspaper advertisement instead of sampling them from treatment settings, in order to avoid helpseeking selfselection biases, which might be considerable in treatment samples. This sampling strategy also helped to cover a broad spectrum of cases of various degrees of severity. In terms of the limitations of this sampling strategy, it needs to be mentioned that our social phobia cases might not be representative for social phobics in general. The ideal design would have been to use a random population sample - a strategy that was not feasible because of financial restrictions. Another limitations is that only the pure social phobia group was matched to the controls, whereas no such matching was feasible for the comorbid and the subthreshold group.

As compared to more recent epidemiological findings in the general population, such as the NCS $[16,17]$, our social phobia cases seemed to be quite similar in terms of gender, marital status, professional status, age of onset, and comorbidity rates, as well as in the severity and current help-seeking behavior. A major apparent difference however, is the higher age in our sample at the time of assessment as well as the greater length of illness. Our sampling procedure resulted in more older subjects willing to be interviewed. In contrast, only a few younger subjects, with more recent onset of the disorder, responded to our advertisement. Thus our findings might be more characteristic for older and chronic cases with social phobia.

\section{Quality of life}

Compared to the controls, pure social phobics uncomplicated by comorbid conditions demonstrated that they experienced a highly significant reduction of current generic quality of life (QOL), in particular with regard to the SF-36 factors of general health, social functioning, general mental health, and role functioning. This was due to emotional, social phobia-related problems and their general health status. The clear majority of all social phobics showed at least marked overall impairments. Subthreshold cases did not differ in any of the scales from pure social phobics, whereas comorbid social phobics were significantly more affected in their quality of life. Remarkably, social phobia of any type examined not only revealed considerable reductions in those SF-36 scores that directly relate to emotional health, but also in those covering general health, bodily pains, and vitality. Since we found no indications of increased health care utilization for somatic illnesses, we have no reason to assume that social phobics might suffer more frequently than controls for manifest somatic illnesses. We rather assume that the life style of people suffering from social phobia for many years might result in a substantially increased risk for ill health.

Given the fact the vast majority of cases were not at the peak of their illness severity at the time of the interview, we can assume considerably stronger reductions of quality of life, especially in terms of the subscales for mental health and social functioning, for more acute cases, than we were able to examine in this study.

The overall reductions in the standardized SF-36 scores of pure social phobia are quite similar to those reported for depressed outpatients [25]. Comorbidity, and in particular the presence of depression, seems to increase considerably the degree of impairments in terms of quality of life. In an attempt to identify which of the characteristics of social phobia predict the degree of reduction in quality of life, we examined a number of clinical variables. Interestingly however, the number of social phobic trigger situations (isolated vs. generalized social phobia) was found to be the only variable significantly related to a reduction in SF-36 scores. Neither duration of illness, age of onset, nor the presence of a current major depression in the CIDI were found to be significantly related to current SF-36 scores. This would suggest that 
the number rather than the symptoms (and not only depressive symptoms alone) contribute to the high degree of disability observed in social phobia.

\section{Disease-specific impairments}

With regards to disabilities, measured by the Liebowitz Disability Self-Rating Scale (LDSRS), we found (as did Schneier et al. [23]), that: (a) social phobia affects most areas of life, but in particular romantic relations, education, career, and family relations; (b) the presence of past and current comorbid conditions increases considerably the frequency of disease-specific impairments; and, (c) that subthreshold social phobia shows only slightly lower overall impairment scores when compared to pure threshold social phobia. From the selfreported disability data, we can describe social phobics as follows. The majority are able to work at a job appropriate to their abilities, but they clearly perform beneath their abilities. They also have a clear impairment in dating activities or marital problems. They had a few friends they meet regularly, but this represented fewer friends than desired. The majority were able to participate in some non-work interest (hobbies, sports), but again, clearly less than desired, due to their avoidance of social activities. In family functioning and the activities of daily living, the group as whole experience some distress but no clear impairment of functioning, except for those who were unemployed. There is a markedly increased risk for suicidal ideation, particularly in the comorbid group.

It is important to note that almost all social phobics indicated considerably higher ratings of impairment for the past, when their symptoms were worst. Thus, current impairments were usually less severe than during the peak of the illness. The peak of severity was rated by most to have occurred in early adulthood (when decisions had to be made relating to educational attainment, professional career, partnership, and friends). In many cases these individuals had obviously learnt to some degree to 'live' and 'cope' with some of their disabilities. Our findings from the LDSRS, as well as from the CIDI, suggest that alcohol use and smoking might play an important role in coping with social phobia problems. The rate for nicotine dependence was almost double the rate observed in the matched control group, and alcohol use disorder rates almost triple. The high risk of dependence for both substance disorders (20.6\% fulfilled dependence criteria) in the subthreshold and the comorbid social phobia group (29.4\%), was especially unexpected and deserves further attention in future studies.

The high scores illustrating disabilities affecting partner and romantic relationships match our findings for the current sociodemographic status. These demonstrated a significantly lower percentage of subjects in all social phobia groups who were never married, as well as higher percentages of divorced subjects. Similarly, the disability scores in the domains of educational, work and career achievement parallel the finding that social phobics were more frequently unemployed and less frequently in the workforce, compared with both the controls as well as with the official unemployment statistics for this age group (German National Bureau of Statistics for 1994, [26], the year this study was conducted: 5.4\%).

\section{Work productivity}

Social phobia also leads to substantial reductions in work productivity and daily life activities. In addition to the elevated unemployment rates, pure and comorbid social phobics were more frequently significantly reduced in their work productivity, as expressed by the number of work days missed and in impairment in work performance. As measured by the WPAI work productivity score, the reduction could be estimated to amount to $12 \%$ in both the pure and the comorbid social phobia group. Furthermore, significantly impaired activities of daily 
living measured in the WPAI underline the above mentioned findings of a reduced quality of life. Unlike these two social phobia groups, subthreshold social phobics revealed only minor reductions in work productivity.

Like most recent epidemiological studies in the US (NCS) [6] and Germany [1], we found that only about one-third of all social phobics received some kind of treatment in the course of their illness. Most frequently, some kind of pharmacological intervention was reported predominantly sedatives and less frequently beta-blockers - prescribed by their primary care doctors for at least a week. Treatments by psychiatrists were extremely rare, but treatment by psychologists was relatively more frequent. Although other indices of current health care use were examined, no clear evidence was found that social phobics, whether comorbid or not, used health services significantly more frequently than the matched control group. However, in interpreting this finding one should acknowledge that in terms of health service utilization, we only examined current health service utilization. We were unable to indicate whether our social phobics were using services more heavily in their previous illness history. Based on additional information about treatment history of our cases, we can assume that most social phobics examined, were generally not content about the treatment effects of their lifetime treatments, and that they remained rather pessimistic about the chances to improve their social phobia problems. This attitude of demoralization in all of the three groups examined might also explain the low current utilization rates of health care services as well as the increased rates of suicidal ideation.

In summary, our findings show that social phobia seems to be a persisting illness, producing a considerable decrease in the quality of life, as well as producing numerous and considerable specific social role impairments and disabilities. Educational attainment, career and work productivity, as well as relationships with others (partner, family, friend), are the domains the most strongly affected. Although comorbidity seems to worsen the overall disability picture, it is also noteworthy that the vast majority of comorbid social phobics described their social phobia as the primary disorder, occurring many years before other comorbid conditions evolved. This might suggest that social phobia in itself might put the individual at a considerable longterm risk for developing depressive, substance use, and possibly other forms of mental disorders. In this respect, special attention should be paid to the critical role of nicotine and alcohol use and the subsequent development to develop substance disorders.

Table I Socio-demographic characteristics of the four comparison groups.

\begin{tabular}{|c|c|c|c|c|c|c|c|c|}
\hline \multirow{3}{*}{ Variables } & \multicolumn{6}{|c|}{ Sacial phobia groups } & \multirow{2}{*}{\multicolumn{2}{|c|}{$\begin{array}{l}\text { Coninols } \\
\text { controls } \\
(\mathrm{n}-65)\end{array}$}} \\
\hline & \multicolumn{2}{|c|}{$\begin{array}{l}\text { puere } S P \\
(\mathrm{n}=65)\end{array}$} & \multicolumn{2}{|c|}{$\begin{array}{l}\text { comorbid } \\
(\mathrm{n}-51)\end{array}$} & \multicolumn{2}{|c|}{$\begin{array}{c}\text { subthreshold } \\
(\mathrm{n}-34)\end{array}$} & & \\
\hline & n & $\%$ & $\mathrm{n}$ & $\%$ & $\mathrm{n}$ & $\%$ & $\mathbf{n}$ & $\%$ \\
\hline Females & 41 & 63.1 & 31 & 60.8 & 20 & 58.8 & 41 & 63.1 \\
\hline Age mean & \multicolumn{2}{|c|}{36.9} & \multicolumn{2}{|c|}{38.0} & \multicolumn{2}{|c|}{35.4} & \multicolumn{2}{|c|}{37.2} \\
\hline $\mathrm{SD}$ & \multicolumn{2}{|c|}{9.6} & \multicolumn{2}{|c|}{9.9} & \multicolumn{2}{|c|}{9.2} & \multicolumn{2}{|c|}{9.4} \\
\hline \multicolumn{9}{|l|}{ Marital statses } \\
\hline Married & 22 & 33.8 & 9 & 17.6 & 10 & 29.4 & 37 & 56.9 \\
\hline Separated & 1 & 1.5 & 2 & 3.9 & 1 & 2.9 & 2 & 3.1 \\
\hline Div & 11 & 16.9 & 8 & 15.7 & 4 & 11.8 & 5 & 7.7 \\
\hline Never married & 31 & 47.7 & 32 & 62.7 & 19 & 55.9 & 21 & 32.3 \\
\hline \multicolumn{9}{|l|}{ Employment } \\
\hline Full time & 32 & 50.0 & 19 & 37.3 & 18 & 52.9 & 31 & 47.7 \\
\hline Part time & 15 & 23.0 & 8 & 15.7 & 6 & 17.6 & 14 & 21.5 \\
\hline Unemployed & 7 & 10.8 & 11 & 21.5 & 4 & 11.8 & 2 & 3.1 \\
\hline Retired & 1 & 1.5 & 2 & 3.9 & - & - & 2 & 3.1 \\
\hline Homemak & 4 & 6.2 & 5 & 9.8 & 4 & 11.8 & 8 & 12.3 \\
\hline Education & 6 & 10.0 & 4 & 7.8 & 2 & 5.9 & 7 & 10.8 \\
\hline Other & - & - & 2 & 3.9 & - & - & 1 & 1.5 \\
\hline
\end{tabular}


Table II Clinical characteristics of the comparison groups.

\begin{tabular}{|c|c|c|c|c|c|c|}
\hline \multirow[t]{2}{*}{ Variables } & \multicolumn{2}{|c|}{ Pure SP $(\mathrm{n}-65)$} & \multicolumn{2}{|c|}{ Comarbid (n-5I) } & \multicolumn{2}{|c|}{ Subshreshold $(\mathrm{n}-34)$} \\
\hline & $\mathrm{n}$ & $\%$ & $\mathrm{n}$ & $\%$ & $\mathrm{n}$ & $\%$ \\
\hline \multicolumn{7}{|l|}{ Type of social phabia } \\
\hline 'Isolated' (less than two situations) & 31 & 47.7 & 10 & 19.6 & 21 & 61.8 \\
\hline 'Generalized' (more than two situations) & 34 & 52.3 & 41 & 80.4 & 13 & 38.2 \\
\hline \multicolumn{7}{|l|}{ Symptoms } \\
\hline Severe anxiety reaction (panic) & 60 & 92.1 & 50 & 98.4 & 23 & 67.8 \\
\hline Persistent avoidance & 54 & 83.6 & 47 & 91.2 & 22 & 63.2 \\
\hline $\begin{array}{l}\text { Frequent endurance } \\
L T \text { belpseeking and severity (CIDI) }\end{array}$ & 8 & 12.4 & 6 & 8.8 & 13 & 36.8 \\
\hline Contacted a doctor & 14 & 21.5 & 16 & 31.4 & 3 & 8.8 \\
\hline Contacted other providers & 9 & 13.8 & 10 & 19.8 & 3 & 8.8 \\
\hline Use of medication & 16 & 24.6 & 15 & 29.4 & 4 & 11.8 \\
\hline \multicolumn{7}{|l|}{ Current (12 month) comorbidity } \\
\hline No current comorbid condition & 65 & 100 & 15 & 18.4 & 29 & 85.3 \\
\hline Major depression & 0 & - & 5 & 9.8 & 1 & 2.9 \\
\hline Dysthymia & 0 & - & 17 & 33.3 & 0 & - \\
\hline Agoraphobia & 0 & - & 16 & 31.4 & 0 & - \\
\hline Panic disorder & 0 & - & 5 & 8.8 & 1 & 2.9 \\
\hline Generalized anxiety disorder & 0 & - & 3 & 5.9 & 0 & - \\
\hline Obsessive compulsive disorder & 0 & - & 5 & 8.8 & 0 & - \\
\hline Eating disorder & 0 & - & 1 & 1.9 & & \\
\hline Nicotine dependence & 26 & 40.0 & 24 & 47.1 & 15 & 44.1 \\
\hline Alcohol abuse & 15 & 23.1 & 5 & 9.8 & 4 & 11.8 \\
\hline Alcohol dependence & 0 & - & 15 & 29.4 & 7 & 20.6 \\
\hline $\begin{array}{l}\text { Drug abuse/dependence } \\
\text { Logat smbstance wse (mean/SD) }\end{array}$ & 3 & 4.6 & 5 & 9.8 & 1 & 2.9 \\
\hline Average number cigarettes/day & \multicolumn{2}{|c|}{$15.2(10.2)$} & \multicolumn{2}{|c|}{$17.3(9.2)$} & \multicolumn{2}{|c|}{$16.8(12.1)$} \\
\hline Alcohol consumption /grams week ${ }^{-1}$ & \multicolumn{2}{|c|}{$50.1(46.1)$} & \multicolumn{2}{|c|}{$75.5(81.7)$} & \multicolumn{2}{|c|}{$42.4(33.9)$} \\
\hline
\end{tabular}

Table III SF-36 quality of life. Subgrouping according to the degree of impaimnent based on SF-36 total scores for social functioning. vitality, and role limitation due to emotional problems.

\begin{tabular}{|c|c|c|c|c|c|c|c|c|}
\hline \multirow{2}{*}{$\begin{array}{l}\text { SF-36 scares: } \\
\text { Degree of } \\
\text { impatiment }\end{array}$} & \multicolumn{2}{|c|}{$\begin{array}{c}\text { Pure } \\
(\mathrm{n}=65)\end{array}$} & \multicolumn{2}{|c|}{$\begin{array}{l}\text { Comorbid } \\
(\mathrm{n}-51)\end{array}$} & \multicolumn{2}{|c|}{$\begin{array}{c}\text { Sububres- } \\
\text { bold } \\
(\mathrm{n}-34)\end{array}$} & \multicolumn{2}{|c|}{$\begin{array}{l}\text { Controls } \\
(\mathrm{n}=65)\end{array}$} \\
\hline & $\mathrm{n}$ & $\%$ & $\mathrm{n}$ & $\%$ & n & $\%$ & $\mathrm{n}$ & $\%$ \\
\hline $\begin{array}{l}\text { Severely impaired } \\
\text { (lower 50) }\end{array}$ & 15 & 23.1 & 26 & 51.0 & 7 & 20.6 & 1 & 1.5 \\
\hline $\begin{array}{l}\text { Markedly impaired } \\
\text { (50 to 69) }\end{array}$ & 16 & 24.6 & 16 & 31.4 & 12 & 35.3 & 2 & 3.1 \\
\hline $\begin{array}{l}\text { No or slight im- } \\
\text { pairment } \\
\text { ( } 70 \text { and above) }\end{array}$ & 34 & 52.3 & 9 & 17.6 & 15 & 44.1 & 62 & 95.4 \\
\hline Total & \multicolumn{2}{|c|}{65100} & \multicolumn{2}{|c|}{51100} & \multicolumn{2}{|c|}{34100} & \multicolumn{2}{|c|}{65100} \\
\hline
\end{tabular}

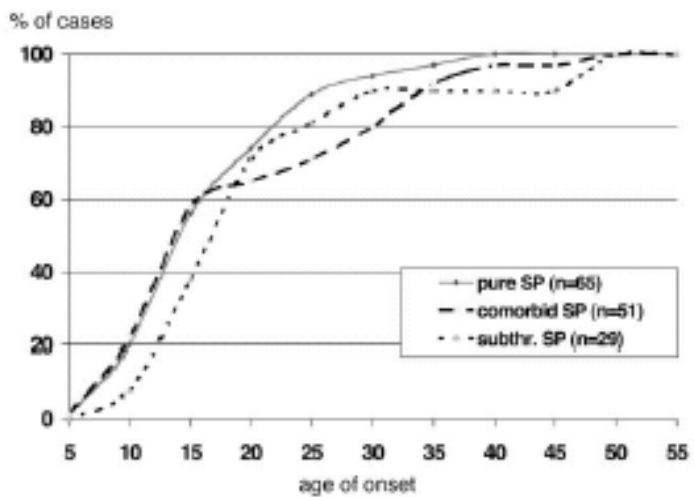

Figure 1. Cumulative probability of age of onset of social phobia by study group. 


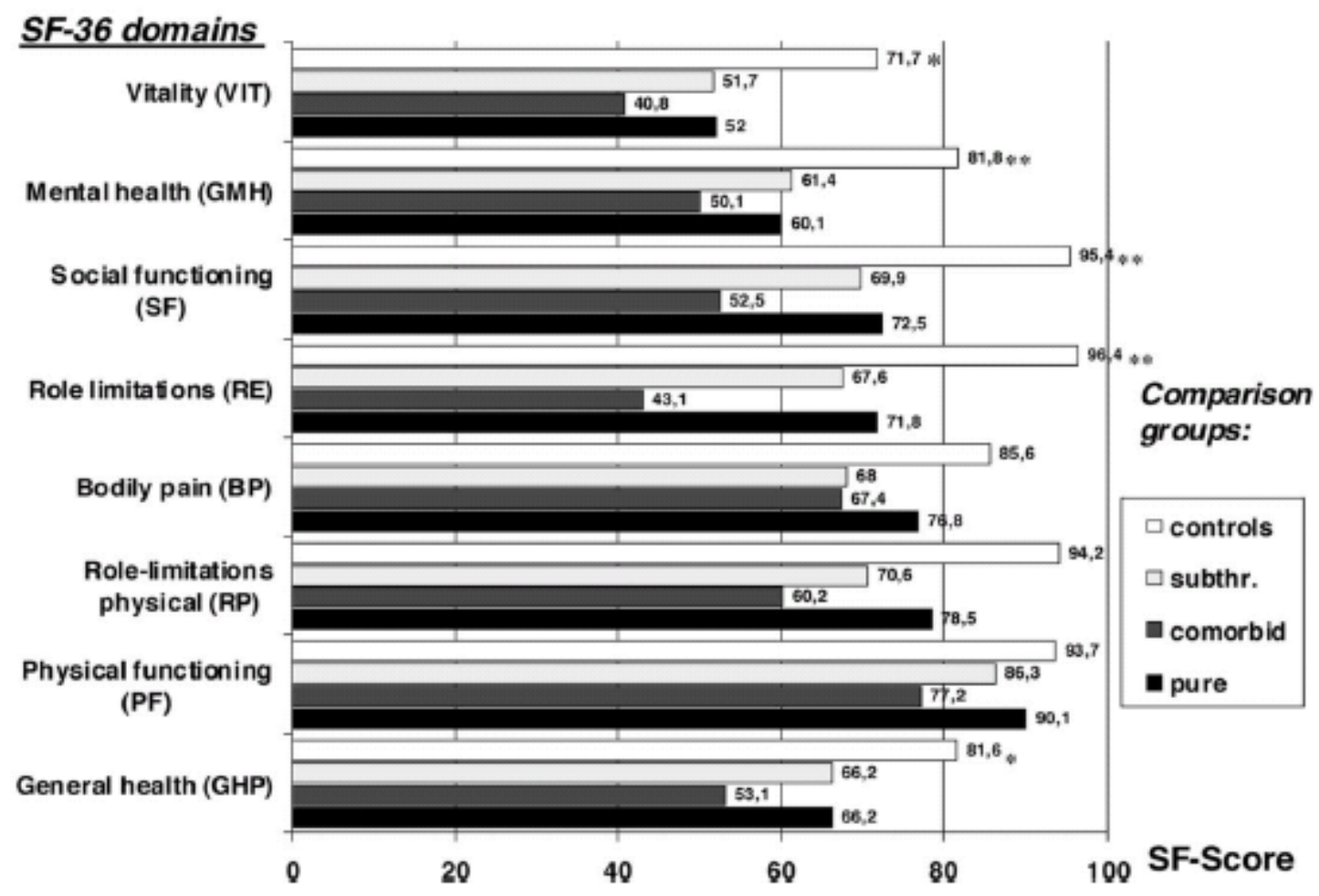

Figure 2. SF-36 standardized mean scores in controls, subthreshold, comorbid, and pure social phobia. Marked comparisons of controls vs pure, comorbid and subthreshold group were all significant * $=p>.05 ;{ }^{* *} p<001$.

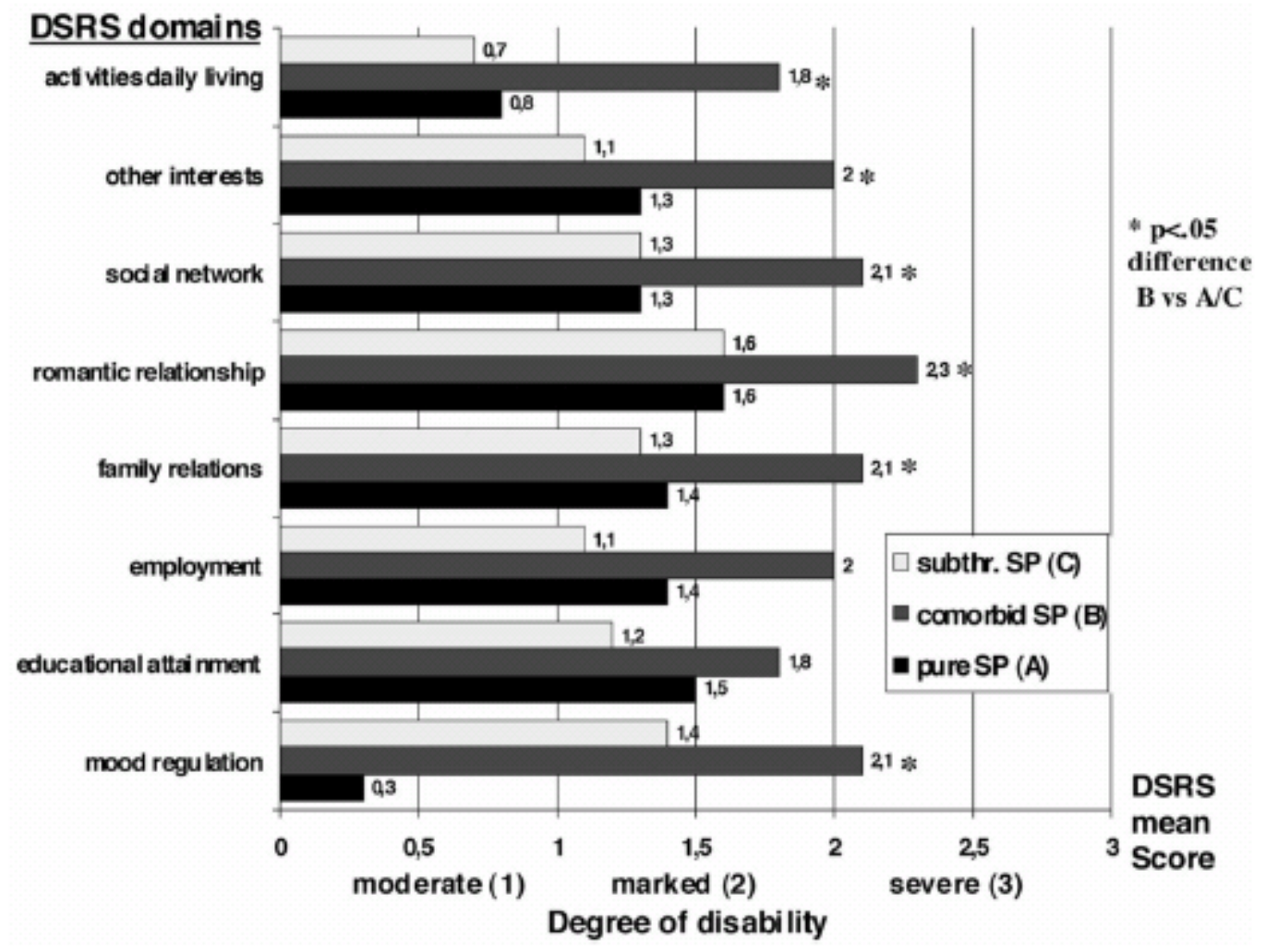

Figure 3. Social phobia related in disabilities in different domains of the DRSR in pure, comorbid, and subthreshold social phobia: DSRS mean scores. 


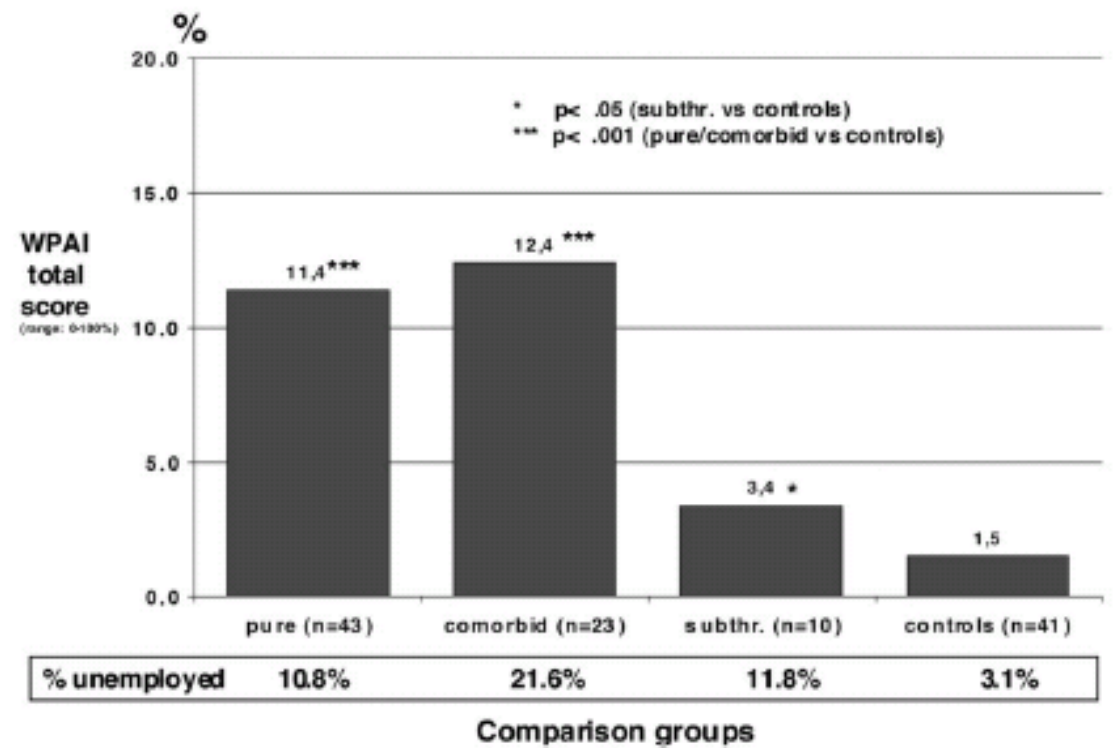

Figure 4. Overall reduction in productivity according to the WPAl in controls, pure, comorbid, and subthreshold social phobia.

\section{Acknowledgements}

Data collection for this study was supported by an unrestricted educational grant from Hoffman La Roche. Data analysis and preparation of this manuscript was supported by an unrestricted educational grant of SmithKline Beecham.

\section{References}

1 Wittchen HU, Stein HB, Kessler RC. Social fears and social phobia in a community sample of adolescents and young adults: prevalence, risk factors, and comorbidity. Psychol Med 1999; 29 : 30923.

2 Angst J, Vollrath M, Merikangas KR, Ernst C. Comorbidity of anxiety and depression in the Zurich cohort study of young adults. In: Maser JD, Cloninger CR, eds. Comorbidity of mood and anxiety disorders. Washington DC: Am Psychiatr Press ; 1990. p. 123-53.

3 Wittchen HU, Essau CA, Zerssen D, Von Krieg CJ, Zaudig M. Lifetime and six-month prevalence of mental disorders in the Munich follow-up study. Eur Arch Psychiatry Clin Neurosci 1992 ; 241 : 247-58.

4 Wacker HR, Müllejans R, Klein KH, Battegay R. Identification of cases of anxiety disorders and affective disorders in the community according to ICD-10 and DSM-III-R by using the composite international diagnostic interview (CIDI). Int J Meth Psychiatr Res 1992 ; 2 : 91-100.

5 Kessler RC, McGonagle KA, Zhao S, Nelson CB, Hughes M, Eshleman S, Wittchen HU, et al. Lifetime and 12-month prevalence of DSM-III-R psychiatric disorders in the United States: results from the National comorbidity survey. Arch Gen Psychiatry 1994 ; 51 : 8-19.

6 Magee WJ, Eaton WW, Wittchen HU, McGonagle KA, Kessler RC. Agoraphobia, simple phobia, and social phobia in the National Comorbidity Survey. Arch Gen Psychiatry 1996 ; 53 : 159-68. 7 Davidson JR, Hughes DC, George LK, Blazer DG. The boundary of social phobia. Exploring the threshold. Arch Gen Psychiatry 1994 ; 51 : 975-83.

8 Liebowitz MR, Gorman JM, Fyer AJ, Klein DF. Social phobia: review of a neglected anxiety disorder. Arch Gen Psychiatry 1985 ; 42 : 729-36.

9 Mullaney JA, Trippet CJ. Alcohol dependence and phobias: clinical description and relevance. $\mathrm{Br} \mathrm{J}$ Psychiatry 1979 ; 135 : 565-73.

10 Borden KH. Social phobia: an overview of treatment strategies. J Clin Psychiatry 1993 ; 54 : 16571. 
11 Merikangas K, Angst J, Eaton W, Canino G, Rubio-Stipec M, Wacker H, et al. Comorbidity and boundaries of affective disorders with anxiety disorders and substance abuse: results of an international task force. Br J Psychiatry, 1996 ; 168 Suppl 30 : 49-58.

12 World Health Organization. Composite International Diagnostic Interview (CIDI): a) CIDIinterview (version 1. 0), b) CIDI-user manual, c) CIDI-training manual, d) CIDI-computer programs. Geneva: World Health Organization ; 1990.

13 Wittchen HU, Semler G. Composite international diagnostic interview (CIDI, version 1.0). Weinheim: Beltz Verlag ; 1990.

14 Semler G, Wittchen HU, Joschke K, Zaudig M, Geiso T, Kaiser S, et al. Test-retest reliability of a standardized psychiatric interview (DIS/CIDI). Eur Arch Psychiatry Neuro Sci 1987 ; 236 : 214-22. 15 Wittchen HU, Robins LN, Cottler L, Sartorius N, Burke J, Regier D, et al. Cross-cultural feasibility, reliability and sources of variance of the composite international diagnostic interview (CIDI). Results of the multicenter WHO/ADAMHA field trials (wave I). Br J Psychiatry 1991 ; 159 : 645-53.

16 Wittchen HU. Reliability and validity studies of the WHO-composite international diagnostic interview (CIDI): a critical review. J Psychiatr Res 1994 ; 28 : 57-84.

17 Wittchen, HU, Zhao S, Abelson JM, Abelson JL, Kessler RC. Reliability and procedural validity of CIDI DSM-III-R phobic disorders. Psychol Med, in press.

18 Ware JE, Sherbourne CD. The MOS 36-item short form health survey (SF-36). I. Conceptual framework and item selection. Med Care 1992 ; 30 : 473-83.

19 McHorney CA, Ware JE, Raczek AE. The MOS 36-item short form health survey (SF-36): II. Psychometric and clinical tests of validity in measuring physical and mental health constructs. Med Care 1993 ; 31 : 247-63.

20 Brazier JE, Harper R, Jones NM, O’Cathain A, Thomas KJ, Usherwood T, et al.. Validating the SF-36 health survey questionnaire: new outcome measure for primary care. Br Med J 1992 ; 305 : $160-4$.

21 McHorney CA, Ware JE, Rogers W, Raczek AE, Lu JF. The validity and relative precision of MOS short- and long-form health status scales and Dartmouth COOP charts. Results from the medical outcomes study. Med Care 1992 ; 305 Suppl : 253-65.

22 Bullinger M, Kirchberger I, Ware J. The German SF-36 health survey. Translation and psychometric testing of a generic instrument for the assessment of health-related quality of life, unpublished.

23 Schneier FR, Heckelman LR, Garfinkel R, Campeas R, Fallon BA, Gitow A, et al. Functional impairment of social phobia. J Clin Psychiatry 1994 ; 55 : 322-31.

24 Reilly MC, Zbrozek AS, Dukes EM. The validity and reproducibility of a work productivity and impairment instrument. PharmacoEconomics 1993 ; 4 : 353-65.

25 Tarlov AR, Ware JE, Greenfield S. The medical outcomes study: an application of methods for monitoring the results of medical care. JAMA 1989 ; 262 : 925-30.

26 Jugend-Gesundheit. Schwerpunktbericht im Rahmen der Gesundheitsberichterstattung des Gesundheitsreferates der Landeshauptstadt München, München, 1997.

27 Weiller I, Bisserbe JC, Bauer P, Lepine JP, Lecrubier Y. Social phobia in general health care. An unrecognized, untreated disabiliting disorder. Br J Psychiatry 1996 ; 168 : 169-74.

28 Safren SA, Heimberg RG, Brown EJ, Holle C. Quality of life in social phobia. Depression Anxiety $1997 ; 4$ : 126-33.

29 Kessler RC, Stang P, Wittchen HU, Stein M, Walters EE. Lifetime comorbidities between social phobia and mood disorders in the US national comorbidity survey. Psychol Med, 1999, in press. 30 Wittchen HU, Beloch E. The impact of social phobia on quality of life. Ont Clin Psychopharmacol 1996 ; 11 Suppl $3: 15-23$. 